\title{
Successful Use of Adalimumab for Treating Pyoderma Gangrenosum with Ulcerative Colitis under Corticosteroid-tapering Conditions
}

\author{
Shintaro Sagami ${ }^{1}$, Yoshitaka Ueno ${ }^{2}$, Shinji Tanaka ${ }^{2}$, Kenta Nagai ${ }^{1}$, \\ Ryohei Hayashi ${ }^{1}$ and Kazuaki Chayama ${ }^{1}$
}

\begin{abstract}
A 52-year-old woman with ulcerative colitis was admitted to our hospital for an ulcerative colitis flare-up under salazosulfapyridine therapy. The symptoms improved with high-dose corticosteroids. After prednisolone was tapered to $10 \mathrm{mg}$, the frequency of diarrhea increased. The diarrhea was accompanied by joint pain and a skin ulcer with abscess formation, which was diagnosed to be pyoderma gangrenosum. The patient was started on adalimumab. A positive response to the adalimumab therapy was observed after 2 weeks, during which time the ulcerative skin lesion healed completely, however, colonic mucosal healing was achieved at 2 months. Therefore, adalimumab appears to be an effective therapeutic option for patients with ulcerative colitis-associated pyoderma gangrenosum.
\end{abstract}

Key words: adalimumab, ulcerative colitis, pyoderma gangrenosum

(Intern Med 54: 2167-2172, 2015)

(DOI: 10.2169/internalmedicine.54.4853)

\section{Introduction}

Pyoderma gangrenosum is a rare, noninfectious, inflammatory neutrophilic dermatosis of unknown etiology (1). Although approximately $50 \%$ of pyoderma gangrenosum cases are associated with an underlying disease, most often inflammatory bowel disease, pyoderma gangrenosum does not necessarily present when the underlying inflammatory bowel disease is not active (2). Therapeutic strategies have been based primarily on immunosuppressive therapy, such as corticosteroids, azathioprine, methotrexate, or cyclosporine (3). Infliximab is a tumor necrosis factor- $\alpha$ blocking agent used for the treatment of various immune-mediated diseases, including ulcerative colitis. Since the introduction of infliximab, several retrospective reviews and studies have reported the efficacy of this biological therapy for pyoderma gangrenosum (4). More recently, there have been reports of pyoderma gangrenosum resolving after treatment with adalimumab, which is a human monoclonal antibody to tumor necrosis factor- $\alpha$. We herein report the first published case of the successful use of adalimumab for a patient with ulcerative colitis who developed pyoderma gangrenosum during the tapering of systemic corticosteroids.

\section{Case Report}

A 52-year-old woman who was diagnosed with steroiddependent chronic active ulcerative colitis 30 years previously was referred to our department with abdominal pain, bloody diarrhea, and fever. Medical treatment had been initiated 30 years prior upon the diagnosis of ulcerative colitis (total colitis), and she continued to receive salazosulfapyridine as a maintenance therapy. Despite this treatment, she was admitted to the hospital in February 2013 for a severe relapse. Colonoscopy showed diffuse continuous mucosal disease and punched-out ulcerations with signs of bleeding [3 points on the Mayo endoscopic subscore (5): Fig. 1A]. Bacterial cultures of the patient's stool were negative. A cytomegalovirus antigenemia assay was negative (Table 1), but cytomegaloviral colitis can be diagnosed in patients with severe ulcerative colitis based on endoscopic findings. Thus,

${ }^{1}$ Department of Medicine and Molecular Science, Hiroshima University, Japan and ${ }^{2}$ Department of Endoscopy, Hiroshima University, Japan Received for publication January 6, 2015; Accepted for publication March 15, 2015

Correspondence to Dr. Yoshitaka Ueno, yueno@ hiroshima-u.ac.jp 


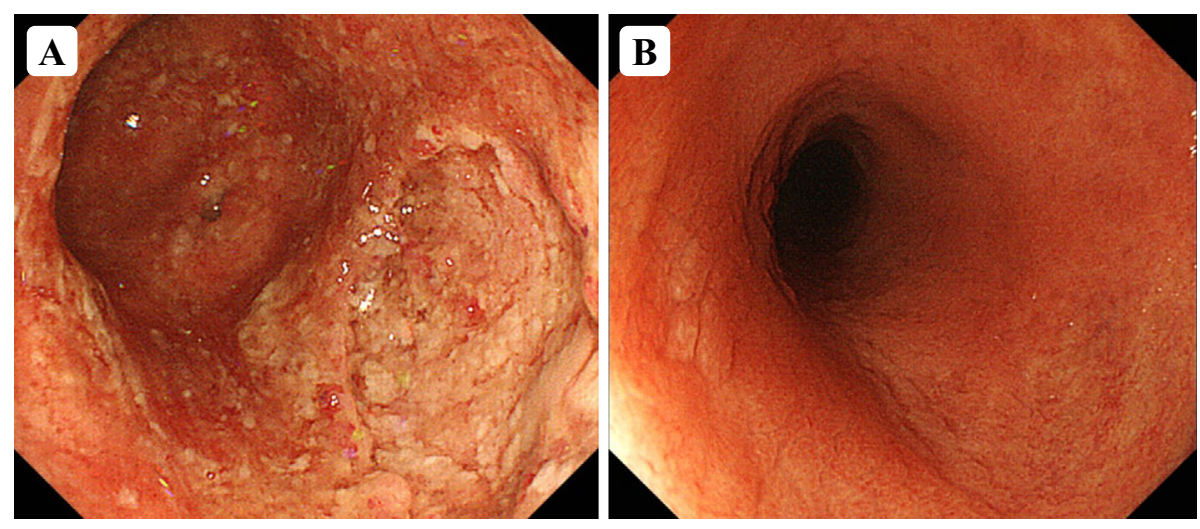

Figure 1. Colonoscopic examination demonstrating a friable, deeply ulcerated mucosa in the rectum at initial visit (A). These ulcers healed 4 months later (B).
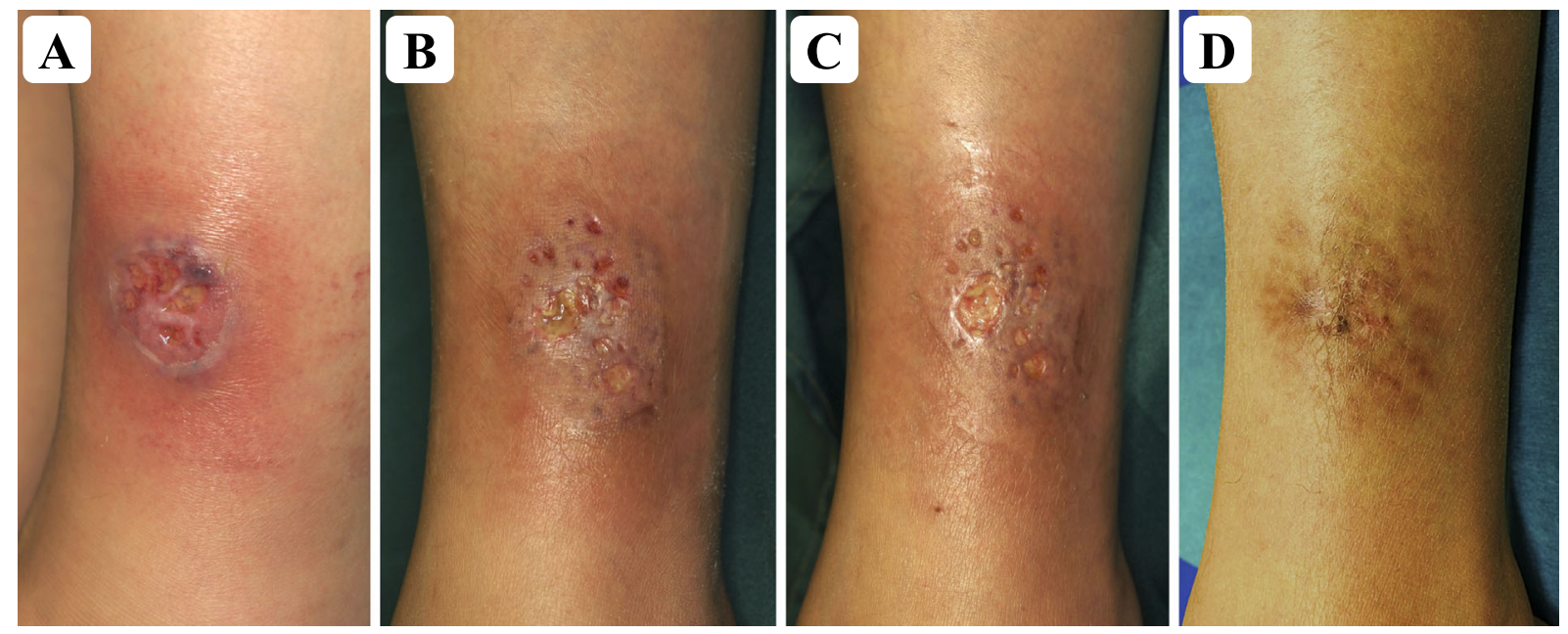

Figure 2. An ulcer $6 \mathrm{~cm}$ in diameter on the lower left thigh (A), with a violaceous undetermined border and a necrotic ground covered with purulent exudate. The lesions showed a rapid improvement under treatment with ADA. Photographs show the left thigh of the same patient shown in (A) after 10 days (B), 15 days (C), and 60 days (D) of follow-up.

oral prednisolone and ganciclovir were initiated at $60 \mathrm{mg} /$ day and $300 \mathrm{mg} /$ day, respectively. Because the bloody stool and diarrhea improved, she was discharged in May 2013 with tapering of prednisolone and the addition of azathioprine $(50 \mathrm{mg} /$ day $)$.

After tapering prednisolone to $10 \mathrm{mg} /$ day in our outpatient department in June, the frequency of diarrhea increased. Because of this, prednisolone therapy was reestablished (20 mg/day). Subsequently, the stool became solid without decreasing the frequency of stools, and the prednisolone dose thereafter was gradually decreased. Joint pain developed at the end of July. During this time, a skin ulcer that measured $6 \mathrm{~cm}$ in diameter appeared on the left thigh (Fig. 2A). The skin lesion gradually enlarged and became more painful. A border formed around the deep ulcer, which bulged and had yellow necrosis characteristics that permeated with purple-red coloring. There was no infectious or neoplastic cause associated with this ulceration. She had no skin disorders related to ulcerative colitis or steroid use.
A biopsy was taken from the dermis depth to the subcutaneous fat tissue, and the abscess formation was recognized as pyoderma gangrenosum (Fig. 3).

Due to the clinical course (Fig. 4), in which the colitis relapse with joint and skin lesions appeared during the tapering of corticosteroids, we opted for the use of adalimumab because the patient refused an increase of corticosteroids due to such side effects as moon face and weight gain. Adalimumab was administered subcutaneously at an induction dose of $160 \mathrm{mg} / 80 \mathrm{mg}$ (Week 0/Week 2) and at a maintenance dose of $40 \mathrm{mg}$ every other week. After the first injection of adalimumab, the patient's diarrhea disappeared, the ulcer began to heal, and the patient's pain improved substantially. Both the skin lesion and the intestinal symptoms significantly improved after the adalimumab induction regimen (Fig. 2B, C). The prednisolone dose was reduced by 5 mg every 2 weeks and was eventually discontinued. Complete healing was achieved after 2 months of treatment (Fig. 2D). Moreover, colonoscopy performed one year after 


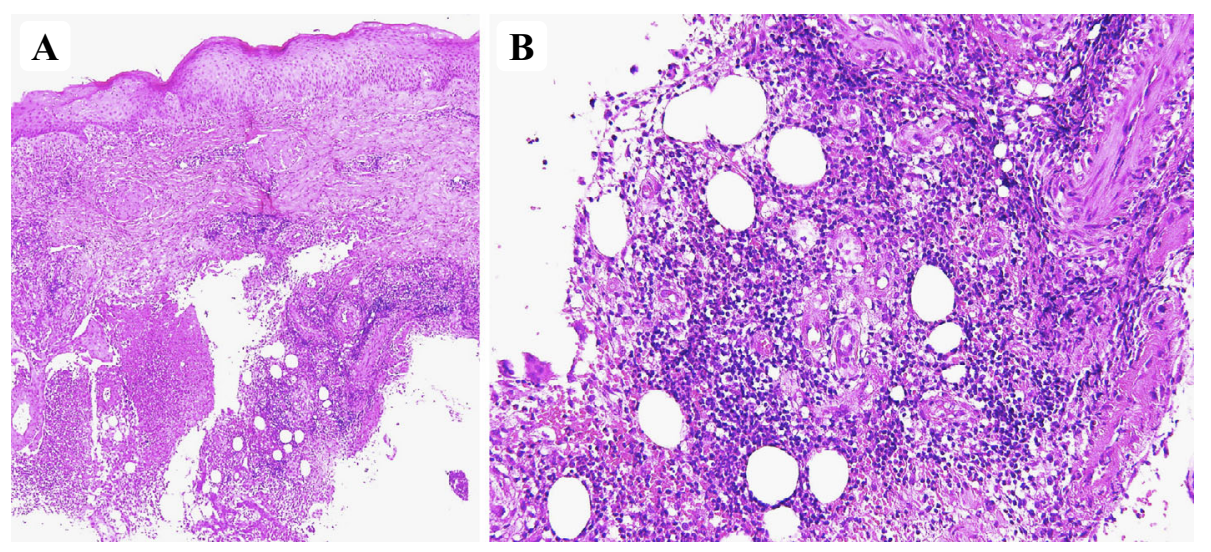

Figure 3. Biopsy of the edge of an ulcer diagnosed as pyoderma gangrenosum. A notable neutrophilic inflammatory infiltrate is visible in the upper dermis. (A) Hematoxylin and Eosin (H\&E) staining; original magnification $\times 20,(B) H \& E$ staining; original magnification $\times 100$.

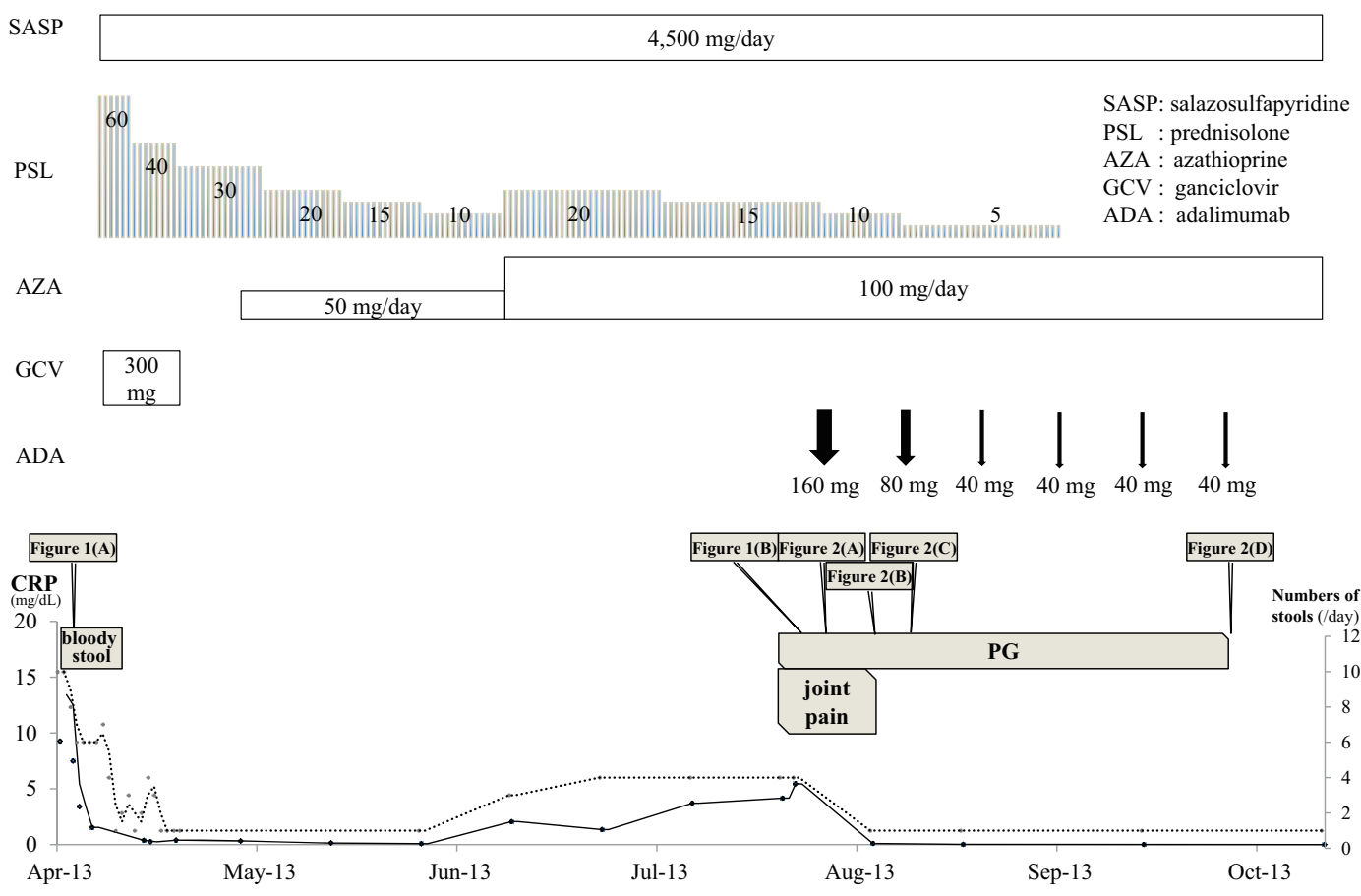

Figure 4. The clinical course of the present case. The solid line and dotted line show the course of CRP and the number of stools per day, respectively.

presentation showed mucosal healing (Fig. 1B).

\section{Discussion}

Pyoderma gangrenosum is a primarily sterile, inflammatory neutrophilic type of dermatitis. Pyoderma gangrenosum occurs in $2 \%$ of patients with ulcerative colitis and is most frequently found on the foreleg, but it can occur anywhere on the body (6). Approximately $50 \%$ of such patients have a background systemic disease, the most common being inflammatory bowel disease, myeloproliferative disorders, and different forms of arthropathy (7).

Pyoderma gangrenosum may not parallel active inflammatory bowel disease in approximately $50 \%$ of patients $(8,9)$. In some patients with inflammatory bowel disease, control of the bowel disease also leads to the control of pyoderma gangrenosum, but this does not occur in all patients. In our case, pyoderma gangrenosum was evident with the relapse of ulcerative colitis during the tapering of prednisolone, suggesting that the increased activity of ulcerative colitis may have led to the appearance of pyoderma gangrenosum.

The precise pathogenesis of pyoderma gangrenosum remains unclear, but its association with autoimmune disorders suggests that disturbances in immune regulation are involved. Immunohistochemical studies in pyoderma gangrenosum ulcers have shown that the neutrophil marker, myeloperoxidase, has a significantly higher expression in the wound bed than in the edge. The expression of CD3 and CD163, the pan $\mathrm{T}$ cell marker and the macrophage marker, respectively, is significantly higher in the wound edge than 
Table 1. Blood Chemical Findings before Initial ADA Injection Show Anemia and an Elevation of the White Blood Cell Count and CRP Level.

\begin{tabular}{|c|c|c|c|c|c|c|}
\hline \multicolumn{2}{|c|}{ Haematology } & \multicolumn{3}{|c|}{ Serum biochemistry } & \multirow{3}{*}{$\begin{array}{l}\text { Cytomegalovirus } \\
\text { antigenemia (C-7HRP) }\end{array}$} & \multirow{3}{*}{$(-)$} \\
\hline WBC & $12,780 \quad / \mu \mathrm{L}$ & T-Bil & 0.3 & $\mathrm{mg} / \mathrm{dL}$ & & \\
\hline $\mathbf{R B C}$ & $378 \times 10^{4} / \mu \mathrm{L}$ & GOT & 9 & $\mathrm{IU} / \mathrm{L}$ & & \\
\hline $\mathrm{Hb}$ & $10.5 \mathrm{~g} / \mathrm{dL}$ & GPT & 10 & $\mathrm{IU} / \mathrm{L}$ & & \\
\hline Ht & $33.7 \%$ & ALP & 119 & $\mathrm{IU} / \mathrm{L}$ & HBs antigen & $(-)$ \\
\hline \multirow[t]{2}{*}{ PIt } & $42.3 \times 10^{4} / \mu \mathrm{L}$ & $\gamma$-GTP & 12 & $\mathrm{IU} / \mathrm{L}$ & HBs antibody & $(+)$ \\
\hline & & LDH & 150 & $\mathrm{IU} / \mathrm{L}$ & HBc antibody & $(-)$ \\
\hline \multirow[t]{2}{*}{ ESR } & $51 \mathrm{~mm} /$ hour & ChE & 249 & $\mathrm{IU} / \mathrm{L}$ & HBV-DNA & not detected \\
\hline & & TP & 6.9 & $\mathrm{~g} / \mathrm{dL}$ & & \\
\hline HbA1c & $6.3 \%$ & Alb & 4.2 & $\mathrm{~g} / \mathrm{dL}$ & Anti-nuclear antibody & negative \\
\hline \multirow[t]{7}{*}{ Casual BS } & $142 \mathrm{mg} / \mathrm{dL}$ & BUN & 23.9 & $\mathrm{mg} / \mathrm{dL}$ & & \\
\hline & & $\mathrm{Cr}$ & 0.69 & $\mathrm{mg} / \mathrm{dL}$ & tuberculin test & negative \\
\hline & & CRP & 1.35 & $\mathrm{mg} / \mathrm{dL}$ & & \\
\hline & & $\mathbf{N a}$ & 142 & $\mathrm{mEq} / \mathrm{L}$ & & \\
\hline & & $\mathbf{K}$ & 4.3 & $\mathrm{mEq} / \mathrm{L}$ & & \\
\hline & & $\mathrm{Cl}$ & 104 & $\mathrm{mEq} / \mathrm{L}$ & & \\
\hline & & $\mathrm{Fe}$ & 15 & $\mu \mathrm{g} / \mathrm{mL}$ & & \\
\hline
\end{tabular}

in the wound bed (10). These findings suggest that not only neutrophils, but also $\mathrm{T}$ cells or macrophages, may be involved in the pathogenesis of pyoderma gangrenosum.

According to an evidence-based consensus on the management of special situations in patients with ulcerative colitis published by the ECCO in 2008, systemic corticosteroids are recommended; however, calcineurin inhibitors or infliximab can also be considered (11).

Several case reports and reviews on the efficacy of adalimumab for the treatment of pyoderma gangrenosum with inflammatory bowel disease have been reported (Table 2). The data from 13 patients were analyzed [9 (69.2\%) females, 7 (53.8\%) with Crohn's disease, 4 (30.8\%) with ulcerative colitis, and $2(15.4 \%)$ with indeterminate disease]. All of the patients received an adalimumab induction schedule of $160 \mathrm{mg} / 80 \mathrm{mg}$ with maintenance doses of $40 \mathrm{mg}$ every other week, with a median period from the first dose of adalimumab to healing of 1.25 months (average \pm SD, 4.1 \pm 2.2 months). Healing was achieved in 12 (92.3\%). Most of the cases were refractory to conventional therapy (steroids and/or cyclosporine), and infliximab was previously attempted in $4(30.8 \%)$ cases, but infliximab was discontinued because of a loss of response and an acute infusion reaction.

Infliximab is the only agent that has been tested in a randomized, controlled trial (4). Although 69\% (20/29) of the patients who received infliximab demonstrated a beneficial response, there was no response in $31 \%(9 / 29)$ of the patients. Adalimumab, therefore, may be an alternative treatment for use in severe pyoderma gangrenosum that has failed to improve with conventional therapy or in patients with adverse reactions or a lack of response to infliximab (12, 13). Furthermore, subcutaneous adalimumab offers the convenience of self-administration. Of the several treatment options available, adalimumab was selected for use in this case because it allows the anti-tumor necrosis factor therapy to be easily administered and because it does not require a lot of time to administer. As in the present case, patients sometimes reject the long-term use of corticosteroids based on the risks of such side effects as acne, weight gain, insomnia, moon face, and osteoporosis. In such circumstances, anti-tumor necrosis factor therapy may be an alternative treatment for pyoderma gangrenosum. A previous comparison of the efficacy of infliximab and adalimumab for Crohn's disease in clinical practice showed no difference in the remission rates between the groups at any time point post-baseline (14). Hence, it follows that patients can select a therapeutic option based on its indications, the mode of administration, side effects, and the scientific evidence of its efficacy and safety. However, so far no comparative examination regarding the effects of anti-tumor necrosis factor agents versus systemic corticosteroids on pyoderma gangrenosum has been conducted. Therefore, clinical trials are needed to evaluate the efficacy and safety of adalimumab as a first-line treatment option for pyoderma gangrenosum.

Some investigators have suggested that treatment of the underlying disease can have a positive impact on the clinical course of pyoderma gangrenosum (15). Adalimumab was approved in Japan for the treatment of adult patients with moderately to severely active ulcerative colitis. Both the safety and efficacy of adalimumab for the treatment of ulcerative colitis in Japanese patients have been recently demonstrated (16).

This case demonstrated the effectiveness of adalimumab on pyoderma gangrenosum. In the event that systemic corti- 
Table 2. Treatment of Pyoderma Gangrenosum with ADA ${ }^{12,13,17-21}$.

\begin{tabular}{|c|c|c|c|c|c|c|c|c|c|c|c|}
\hline No. & Age & Sex & $\begin{array}{l}\text { IB } \\
\mathrm{D}\end{array}$ & complications & $\begin{array}{l}\text { disease } \\
\text { duration } \\
\text { (Month) }\end{array}$ & $\begin{array}{l}\text { size } \\
(\mathrm{cm})\end{array}$ & $\begin{array}{l}\text { period up to } \\
\text { the healing } \\
\text { (Month) }\end{array}$ & Location & pre-medication & $\begin{array}{l}\text { The year of } \\
\text { publication }\end{array}$ & Reference \\
\hline 1 & 38 & $\mathrm{~F}$ & $\begin{array}{l}\text { IB } \\
\text { D }\end{array}$ & N/A & 6 & 8 & 3 & left thigh & AZA, IFX, Tac ointment, IVIG, CyA, PSL20mg & 2006 & 12 \\
\hline 2 & 61 & $\mathrm{~F}$ & $\begin{array}{l}\text { IB } \\
\mathrm{D}\end{array}$ & $\mathrm{N} / \mathrm{A}$ & 60 & N/A & 5 & both pretibial areas & PSL, Mycophenolate mofetil, etanercept, IFX & 2007 & 17 \\
\hline 3 & 13 & $\mathrm{~F}$ & $\mathrm{CD}$ & N/A & N/A & 2.5 & $\begin{array}{l}50 \% \\
\text { improvement }\end{array}$ & peristomal & intralesional triamcinolone injection & 2009 & 18 \\
\hline 4 & 18 & $\mathrm{~F}$ & $\mathrm{CD}$ & $\mathrm{N} / \mathrm{A}$ & N/A & 3 & 1.5 & peristomal & 6-MP, PSL, CyA, stomal re-location, local steroid injection & 2009 & 18 \\
\hline 5 & 38 & $\mathrm{~F}$ & $\mathrm{CD}$ & N/A & N/A & 3 & 2 & lower left thigh & 5-ASA, PSL, Cyclophosphamid & 2009 & 13 \\
\hline 6 & 36 & M & $\mathrm{CD}$ & $\mathrm{N} / \mathrm{A}$ & N/A & N/A & 2 & lower limbs & AZA & 2011 & 19 \\
\hline 8 & 33 & $\mathrm{M}$ & $\mathrm{CD}$ & $\mathrm{N} / \mathrm{A}$ & N/A & N/A & 1 & lower limbs & IFX & 2011 & 19 \\
\hline 9 & 43 & $\mathrm{~F}$ & $\mathrm{UC}$ & N/A & N/A & N/A & 1 & Universal & 5-ASA, AZA, CyA, IFX, & 2011 & 19 \\
\hline 10 & 35 & $\mathrm{~F}$ & $\mathrm{CD}$ & N/A & N/A & $\mathrm{N} / \mathrm{A}$ & 1 & $\mathrm{~N} / \mathrm{A}$ & N/A & 2012 & 20 \\
\hline 11 & 42 & $\mathrm{~F}$ & $\mathrm{UC}$ & N/A & N/A & N/A & 1 & N/A & N/A & 2012 & 20 \\
\hline 12 & 30 & $\mathrm{M}$ & $\mathrm{UC}$ & N/A & N/A & N/A & 1 & N/A & $\mathrm{N} / \mathrm{A}$ & 2012 & 20 \\
\hline 13 & 46 & $\mathrm{~F}$ & $\mathrm{UC}$ & $\begin{array}{l}\text { Basedow disease, } \\
\text { Rheumatoid arthritis }\end{array}$ & N/A & N/A & 8 & peristomal & Tac ointment, methylprednisolone & 2014 & 21 \\
\hline 14 & 53 & $\mathrm{~F}$ & UC & N/A & 1 & 6 & 2 & lower left thigh & 5-ASA, PSL, AZA & 2015 & Author \\
\hline
\end{tabular}

SASP: salazosulfapyridine, PSL: prednisolone, AZA: azathioprine, ADA: adalimumab, CyA: cyclosporine, Tac: Tacrolimus, 6-MP: mercaptopurine,

5-ASA: Mesalamine, N/A: not applicable, IBD: inflammatory bowel disease, CD: Crohn's disease, UC: ulcerative colitis, F: female, M: male

costeroids are not available, adalimumab may therefore be an alternative treatment for pyoderma gangrenosum.

The authors state that they have no Conflict of Interest (COI).

\section{References}

1. Marzano AV, Trevisan V, Lazzari R, Crosti C. Pyoderma gangrenosum: study of 21 patients and proposal of a 'clinicotherapeutic' classification. J Dermatolog Treat 22: 254-260, 2011.

2. Levine JS, Burakoff R. Extraintestinal manifestations of inflammatory bowel disease. Gastroenterol Hepatol (NY) 7: 235-241, 2011.

3. Reichrath J, Bens G, Bonowitz A, Tilgen W. Treatment recommendations for pyoderma gangrenosum: an evidence-based review of the literature based on more than 350 patients. J Am Acad Dermatol 53: 273-283, 2005.

4. Brooklyn TN, Dunnill MG, Shetty A, et al. Infliximab for the treatment of pyoderma gangrenosum: a randomised, double blind, placebo controlled trial. Gut 55: 505-509, 2006.

5. Schroeder KW, Tremaine WJ, Ilstrup DM. Coated oral 5aminosalicylic acid therapy for mildly to moderately active ulcerative colitis. A randomized study. N Engl J Med 317: 1625-1629, 1987.

6. Mir-Madjlessi SH, Taylor JS, Farmer RG. Clinical course and evolution of erythema nodosum and pyoderma gangrenosum in chronic ulcerative colitis: a study of 42 patients. Am J Gastroenterol 80: 615-620, 1985.

7. Agrawal D, Rukkannagari S, Kethu S. Pathogenesis and clinical approach to extraintestinal manifestations of inflammatory bowel disease. Minerva Gastroenterol Dietol 53: 233-248, 2007.

8. Lichtenstein GR, Abreu MT, Cohen R, Tremaine W. American Gastroenterological Association Institute technical review on corti- costeroids, immunomodulators, and infliximab in inflammatory bowel disease. Gastroenterology 130: 940-987, 2006.

9. Agarwal A, Andrews JM. Systematic review: IBD-associated pyoderma gangrenosum in the biologic era, the response to therapy. Aliment Pharmacol Ther 38: 563-572, 2013.

10. Marzano AV, Cugno M, Trevisan V, et al. Role of inflammatory cells, cytokines and matrix metalloproteinases in neutrophilmediated skin diseases. Clin Exp Immunol 162: 100-107, 2010.

11. Biancone L, Michetti P, Travis S, et al. European evidence-based consensus on the management of ulcerative colitis: special situations. J Crohns Colitis 2: 63-92, 2008.

12. Fonder MA, Cummins DL, Ehst BD, Anhalt GJ, Meyerle JH. Adalimumab therapy for recalcitrant pyoderma gangrenosum. J Burns Wounds 5: e8, 2006.

13. Zold E. Successful use of adalimumab for treating fistulizing Crohn's disease with pyoderma gangrenosum: two birds with one stone. World J Gastroenterol 15: 2293, 2009.

14. Patil SA, Rustgi A, Langenberg P, Cross RK. Comparative effectiveness of anti-TNF agents for Crohn's disease in a tertiary referral IBD practice. Dig Dis Sci 58: 209-215, 2013.

15. Ruocco E, Sangiuliano S, Gravina AG, Miranda A, Nicoletti G. Pyoderma gangrenosum: an updated review. J Eur Acad Dermatol Venereol 23: 1008-1017, 2009.

16. Suzuki Y, Motoya S, Hanai $\mathrm{H}$, et al. Efficacy and safety of adalimumab in Japanese patients with moderately to severely active ulcerative colitis. J Gastroenterol 49: 283-294, 2014.

17. Pomerantz RG, Husni ME, Mody E, Qureshi AA. Adalimumab for treatment of pyoderma gangrenosum. Br J Dermatol 157: 12741275, 2007.

18. Alkhouri N, Hupertz V, Mahajan L. Adalimumab treatment for peristomal pyoderma gangrenosum associated with Crohn's disease. Inflamm Bowel Dis 15: 803-806, 2009.

19. Carinanos I, Acosta MB, Domenech E. Adalimumab for pyoderma 
Intern Med 54: 2167-2172, 2015 DOI: 10.2169/internalmedicine.54.4853

gangrenosum associated with inflammatory bowel disease. Inflamm Bowel Dis 17: E153-E154, 2011.

20. Suárez-Pérez JA, Herrera-Acosta E, López-Navarro N, et al. Pyoderma gangrenosum: a report of 15 cases and review of the literature. Actas Dermosifiliogr 103: 120-126, 2012.
21. Cerdán-Santacruz C, Caparrós-Sanz MR, Lancharro-Bermúdez M, Mendoza-Hernández JL, Cerdán-Miguel J. Peri-ileostomy pyoderma gangrenosum. Case report. Rev Esp Enferm Dig 106: 285288, 2014.

\section{(C) 2015 The Japanese Society of Internal Medicine} http://www.naika.or.jp/imonline/index.html 